\title{
Myc and Max associate in vivo
}

\author{
Elizabeth M. Blackwood, ${ }^{1}$ Bernhard Lüscher, ${ }^{2}$ and Robert N. Eisenman \\ Division of Basic Sciences, Fred Hutchinson Cancer Research Center, Seattle, Washington 98104 USA; ${ }^{1}$ Department of \\ Pathology, School of Medicine, University of Washington, Seattle, Washington 98195 USA
}

\begin{abstract}
Max is a helix-loop-helix zipper protein that associates in vitro with Myc family proteins to form a sequence-specific DNA-binding complex. We show here, by means of a coimmunoprecipitation assay with anti-Myc and anti-Max antibodies, that Myc and Max are associated in vivo and essentially all of the newly synthesized Myc can be detected in a complex with Max. This complex possesses specific DNA-binding activity for CACGTG-containing oligonucleotides. Although Max itself is a highly stable protein, Myc is rapidly degraded during or after its association with Max. In vivo Max is shown to be a nuclear protein phosphorylated by casein kinase II, and alternatively spliced forms of Max are expressed in cells. Furthermore, the levels of Max expression are equivalent in quiescent, mitogen-stimulated, and cycling cells. We conclude that the highly regulated rate of Myc biosynthesis is likely to be a limiting step in the formation of Myc:Max complexes.
\end{abstract}

[Key Words: Helix-loop-helix zipper protein; Myc family proteins; Myc:Max complexes]

Received September 25, 1991; revised version accepted November 4, 1991.

The proteins encoded by the c-myc, L-myc and N-myc proto-oncogenes are short-lived nuclear phosphoproteins that possess DNA-binding and protein dimerization domains structurally related to those found in an increasing number of transcription factors (Jones 1990; Lüscher and Eisenman 1990; Penn et al. 1990). For this class of factors dimerization is mediated by a putative helixloop-helix region that in some cases (as in the Myc family proteins) is contiguous with a leucine zipper motif (HLH-Zip). Dimerization is required for specific DNA binding by the short stretch of basic amino acids (b) that precedes the HLH-Zip region (Benezra et al. 1990; Davis et al. 1990; Jones 1990). A major problem in elucidating the function of Myc family proteins has been the inability to define either a dimerization partner or a specific DNA sequence with which Myc interacts (for review, see Lüscher and Eisenman 1990).

Recent work, however, has led to inroads into both of these problems. First, c-Myc has been demonstrated to possess specific DNA-binding activity. Several groups have demonstrated that either the c-Myc bHLH-Zip domain, a chimeric protein containing the basic region of c-Myc with a heterologous HLH domain, or full-length c-Myc are all capable of specifically binding the nucleotide sequence CACGTG (Blackwell et al. 1990; Halazonetis and Kandil 1991; Kerkhoff et al. 1991; Prendergast and Ziff 1991). The binding activity detected for c-Myc is weak in that it requires high concentrations of c-Myc protein. This is presumably due to the low efficiency with which Myc can functionally homodimerize

${ }^{2}$ Present address: Institute for Molecular Biology, Medizinische Hochschule Hannover OE5250, D-3000 Hannover 61, Germany.
(Dang et al 1989; Smith et al. 1990). Second, a dimerization partner for Myc family proteins has been identified. By using a functional cloning strategy a novel human cDNA was isolated that encodes a bHLH-Zip protein dubbed Max. Max associates in vitro with the c-Myc, $\mathrm{N}-\mathrm{Myc}$, and L-Myc proteins but not with other bHLHZip proteins tested (Blackwood and Eisenman 1991). A murine homolog of Max has also been identified (Prendergast et al. 1991). Association between Myc and Max requires the HLH-Zip regions of both proteins (Blackwood and Eisenman 1991; Prendergast et al. 1991). In addition, the human c-Myc:Max complex binds to the CACGTG DNA sequence in a sequence-specific manner under conditions where Myc or Max alone display relatively weak binding. This DNA binding is dependent on the basic region as well as the HLH-Zip domains of both partners (Blackwell et al. 1990; Blackwood and Eisenman 1991; Prendergast et al. 1991).

All of these studies on Myc:Max interaction have been carried out by using bacterially expressed or in vitrotranslated proteins. To examine potential biological roles for the Myc:Max complex we have identified and characterized Max in vivo and demonstrated that the two proteins can be coimmunoprecipitated from cell lysates.

\section{Results \\ $\max$ encodes $p 21$ and $p 22$ proteins in vivo}

To study Max in vivo we produced an antiserum against a purified fusion protein containing the 124 carboxy-terminal residues of human Max linked to the carboxyl terminus of glutathione-S-transferase (GST-MaxC124) 
(see Materials and methods). The anti-GST-MaxC124 serum (anti-Max) was initially tested in immunoprecipitation using whole-cell lysates prepared from $\left[{ }^{35} \mathrm{~S}\right] \mathrm{me}$ thionine-labeled human Burkitt's lymphoma cells (Manca). SDS-PAGE analysis of an anti-Max immunoprecipitate revealed a predominant doublet with relative molecular masses of 21 and $22 \mathrm{kD}$, which was not recognized by the cognate preimmune serum (Fig. 1A). Immunoprecipitation of the $21-$ and $22-\mathrm{kD}$ proteins could be inhibited competitively by excess GST-MaxC124 protein but not by excess GST alone, suggesting that p21/22 are recognized through determinants specific to the Max segment of the immunogen. Numerous minor protein bands were also present in the anti-Max immunoprecipitate, but as these bands were present in precipitates formed with preimmune serum and were not blocked with excess GST-Max protein, we assume that they are the result of nonspecific adsorption to the immune complex.

To determine whether $\mathrm{p} 21 / 22$ are structurally related to Max we compared two-dimensional $\left[{ }^{35} \mathrm{~S}\right]$ methionine tryptic peptide maps of the protein generated by in vitro transcription-translation of the p21 Max cDNA clone (Blackwood and Eisenman 1991) and of the p21/22 proteins from Manca cells. Figure 1B shows that the labeled peptide patterns of the in vivo- and in vitro-generated proteins are superimposable, demonstrating that the p21/22 proteins recognized by anti-Max from Manca cells are highly related to Max.

As both p21 and p22 proteins can be identified in Manca, as well as other cell types (Fig. 1A and data not shown), it was important to determine the relationship between the two proteins. They did not appear to be differentially phosphorylated forms of the same protein as phosphatase treatment did not resolve the p21/22 doublet into a single species (data not shown). In addition, we could find no evidence for a precursor-product relationship between the two proteins (see Fig. 3, below). Previous work had identified two Max cDNAs differing only by the addition of a 9-amino-acid segment aminoterminal to the basic region (Blackwood and Eisenman 1991; Prendergast et al. 1991). In vitro translation of the two variant cDNAs (Fig. 1C, left) shows that they differ in apparent molecular mass by $\sim 1 \mathrm{kD}$ but are nonetheless easily resolved as a doublet on SDS-PAGE. Figure 1C (right) shows that their individual electrophoretic mobilities are identical to those of $\mathrm{p} 21$ and p22 immunoprecipitated from Manca cells with anti-Max. These data suggest that $\mathrm{p} 21$ and $\mathrm{p} 22$ are Max proteins that differ by the 9-amino-acid insertion [note that the 9-amino-acid insertion would not be expected to contribute to the tryptic peptide pattern shown in Fig. $1 \mathrm{~B}$, as the initiating
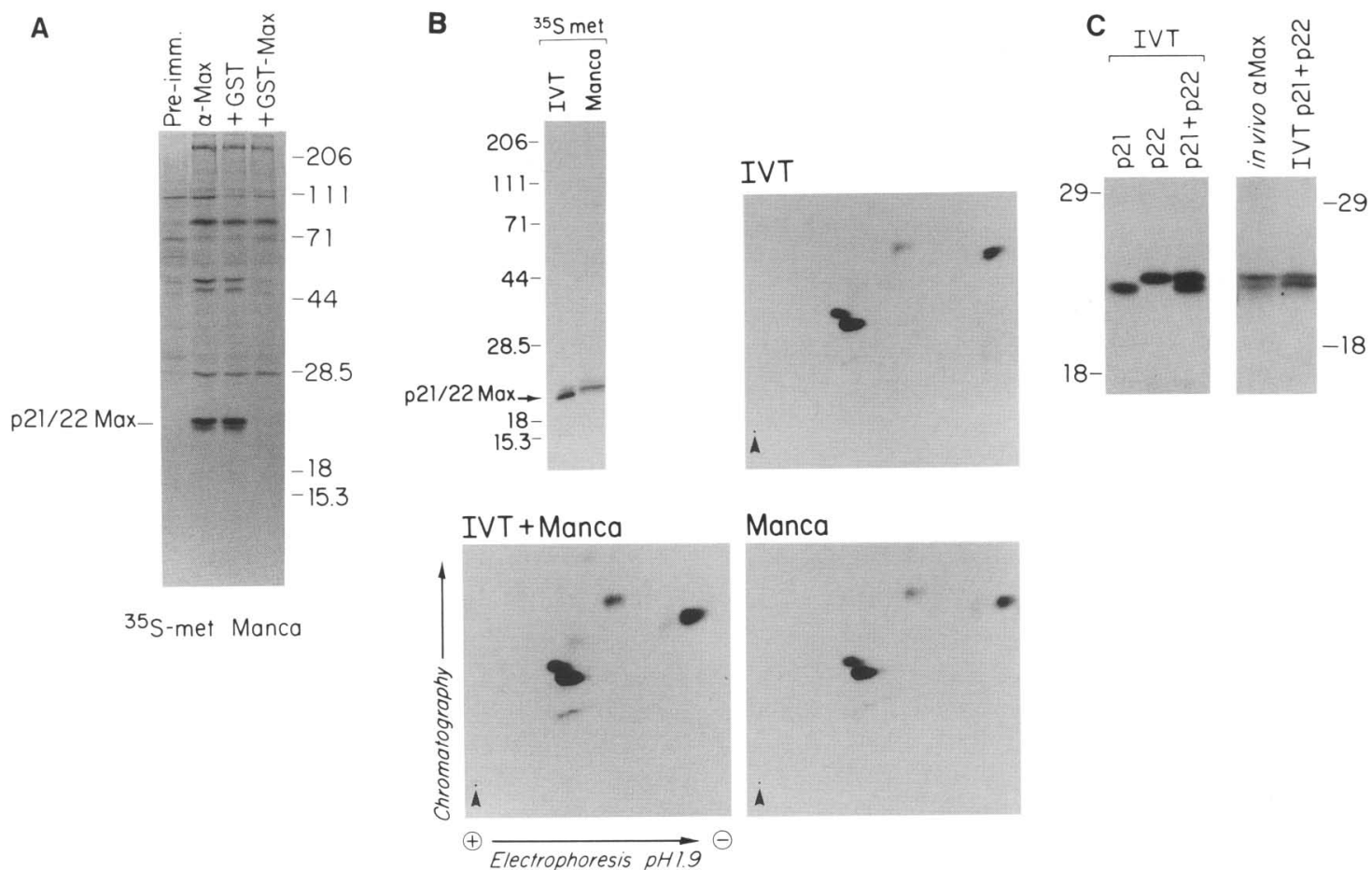

Figure 1. Identification of Max polypeptides in vivo. (A) Max protein was immunoprecipitated from $\left[{ }^{35} S\right]$ methionine-labeled Manca cells using anti-GST-MaxC124 ( $\alpha$-Max). Preimmune serum (Pre-imm) served as a background control, whereas excess immunogen (GST or GST-Max) was used to compete for specific anti-Max binding. (B, upper left) SDS-PAGE analysis of the immunoprecipitated and in vitro-translated proteins used for peptide mapping; $\left(B\right.$, lower left and right) two-dimensional tryptic peptide maps of $\left[{ }^{35} S \mid\right.$ methionine-labeled protein comparing in vitro-translated p21 Max (IVT) with in vivo-labeled p21/22 Max proteins (Manca). (C) The two Max cDNAs (IVT p21 and p22) were translated in a reticulocyte lysate and compared in one-dimensional SDS-PAGE with in vivolabeled Max polypeptides (in vivo $\alpha$ Max). 
amino-terminal $\left[{ }^{35} \mathrm{~S}\right]$ methionine of Max is likely to be removed (Moerschell et al. 1990)]. On the basis of antigenicity, electrophoretic mobility, and two-dimensional peptide mapping analysis, we conclude that $\mathrm{p} 21$ and p22 are encoded by max.

\section{p21/22 ${ }^{\text {ax }}$ are highly stable nuclear proteins phosphorylated by casein kinase II}

Proteins belonging to the Myc family have long been characterized as nuclear phosphoproteins (see Eisenman 1989). That Max is also nuclear can be demonstrated by immunofluorescence analysis of fixed HeLa cells as described in Materials and methods. Anti-Max produces granular nuclear staining exclusive of nucleoli, as observed for Myc (Fig. 2A) (Abrams et al. 1982). In addition, both the p2l and $\mathrm{p} 22$ Max proteins appear to be predominantly nuclear, as shown by cell fractionation experiments (data not shown). That Max is a phosphoprotein was demonstrated by immunoprecipitation of radioactive p21/22 from ${ }^{32} \mathrm{PO}_{4}$-labeled Manca cells (Fig. 2B).

Several major in vivo phosphorylation sites on c-Myc have been shown to correspond to those phosphorylated by casein kinase II (CKII) in vitro (Lüscher et al. 1989). CKII specifically phosphorylates serine or threonine residues within clusters of acidic amino acids, with an ap- parently absolute requirement for an acidic residue 3 amino acids carboxy-terminal to the target serine/threonine (Kuenzel et al. 1987). Because Max also contains such putative CKII consensus phosphorylation sites we determined whether CKII would phosphorylate Max in vitro by treating immunoprecipitated $\mathrm{p} 21 / 22$ Max with purified CKII and $\left[\gamma^{-32}\right.$ P]ATP. Figure 2B shows that radiolabeled phosphate was specifically incorporated into both Max proteins. Note that the immunoglobulins, present in large amounts in the anti-Max immunoprecipitate, are not labeled with CKII, indicating that the phosphorylation of Max is potentially specific. It was important to determine whether the sites of this in vitro phosphorylation of Max by CKII correspond to regions phosphorylated in vivo. Therefore, we compared tryptic phosphopeptide maps of in vivo and in vitro ${ }^{32} \mathrm{PO}_{4}$-labeled Max and found them to be identical (B. Lüscher, unpubl.). Thus, both Max and Myc proteins appear to be in vivo targets for CKII phosphorylation.

Myc proteins have extraordinarily short half-lives, on the order of 20-30 min (Hann and Eisenman 1984; Lüscher and Eisenman 1988; Waters et al. 1991). In contrast, both Max proteins are highly stable, as demonstrated by the pulse-chase analysis carried out in human K562 cells and shown in Figure 3. No change in the levels of pulse-labeled Max is detectable $6 \mathrm{hr}$ after removal of label, and Max appears stable even after a 24-hr chase

A
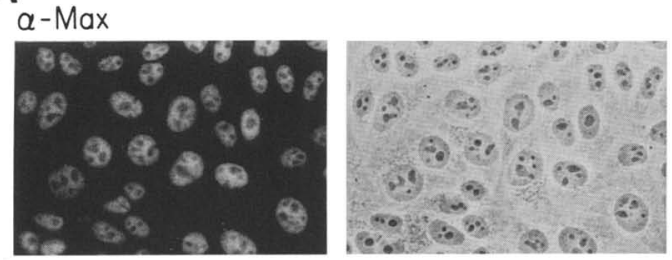

\section{Max block}
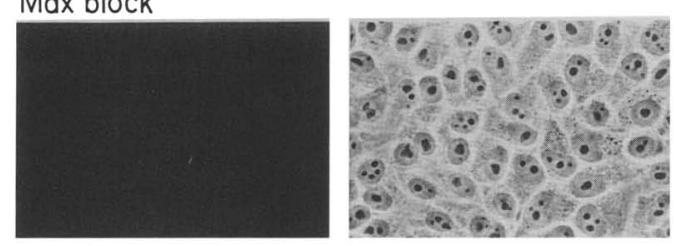

$\alpha-$ Myc
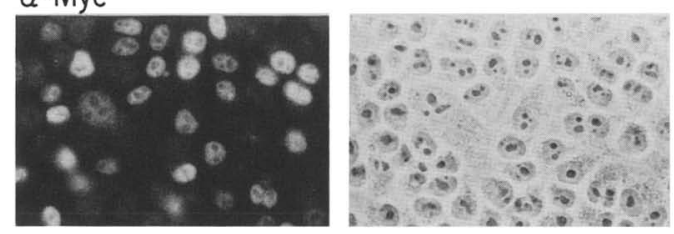

Prei. $\alpha-M y c$
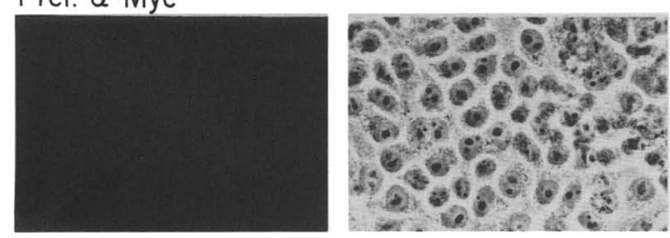

B

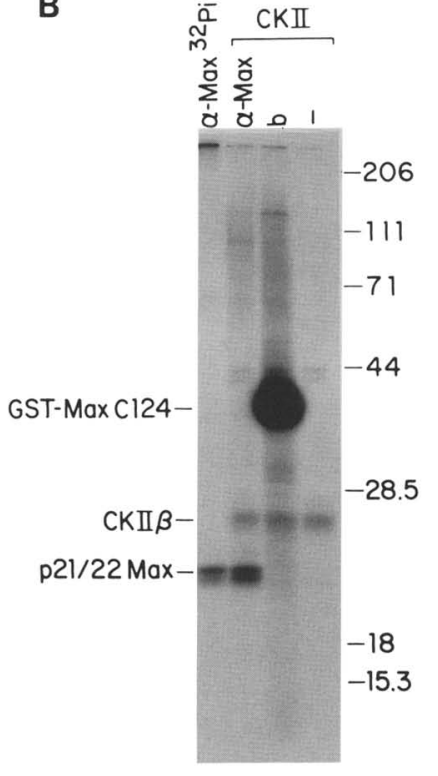

Figure 2. Nuclear localization and phosphorylation of $\alpha$-Max polypeptides. (A) Subcellular localization of Max protein was assayed by indirect immunofluorescence on fixed HeLa cells. Anti-Max and polyclonal anti-Myc immunoreactive proteins were detected with FITClabeled goat anti-rabbit immunoglobulin secondary reagent. Excess immunogen (Max block) or preimmune serum (Prei $\alpha$-Myc) was used as negative control, respectively. Phase-contrast images of the immunostained cells are shown at right. (B) Max polypeptides were immunoprecipitated from $\left[{ }^{32} \mathrm{P}\right]$ orthophosphate-labeled cells $\left(\alpha-\mathrm{Max}^{32} \mathrm{Pi}\right)$ or from unlabeled cells and phosphorylated in vitro with casein kinase II (CKII, $\alpha$-Max). The immunogen (GST-MaxC124) served as an excellent substrate for CKII when added as a blocking reagent (b). Autophosphorylation of the $\beta$ subunit of CKII $(-)$ is shown in the enzyme only control. 


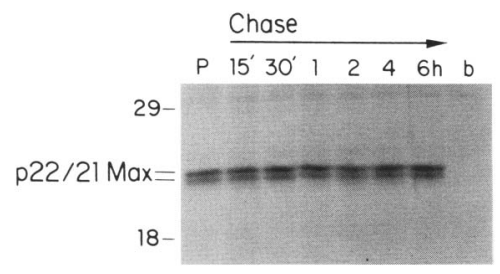

Figure 3. Stability of the Max polypeptides. To analyze protein stability, K562 cells were pulse-labeled with $\left[{ }^{35}\right.$ S]methionine for $30 \mathrm{~min}(\mathrm{P})$ and chased for various lengths of time in the presence of excess nonradioactive methionine. Samples were immunoprecipitated under high-stringency conditions with anti-Max and subjected to SDS-PAGE. GST-MaxC124 was used to block specific immunoprecipitation (b).

period (data not shown). In addition, the relative levels of p21 and p22 Max are unaltered during the chase period, consistent with the idea that the two proteins are independent translation products (Fig. 3). Similar results have been obtained in several human cell types as well as in avian and murine cells; thus, high stability is likely to be characteristic of Max protein (data not shown).

\section{Myc and Max associate in vivo}

In vitro c-Myc homodimerizes poorly, if at all (Blackwell et al. 1990; Smith et al. 1990; Prendergast and Ziff 1991), whereas Max self-associates but preferentially forms heterodimers with c-Myc (Blackwood and Eisenman 1991). A major question raised by the in vitro demonstration of Myc:Max association is whether these proteins also interact in vivo. To answer this question we began by examining the conditions required for immunoprecipitation of Myc from cells. Analyses of Myc proteins by immunoprecipitation are frequently carried out using a mixture of nonionic and ionic detergents that permit efficient extraction of Myc from nuclei and decrease nonspecific binding of proteins to the immunocomplex (Abrams et al. 1982; Hann et al. 1983; Eisenman et al. 1985; Ramsay et al. 1986). However, as deoxycholate and SDS disrupt the Myc:Max complex formed after in vitro translation of both proteins (data not shown), in vivo association between Myc and Max might be similarly disrupted under standard high-stringency immunoprecipitation conditions (see Materials and methods). The Myc:Max oligomers, however, formed in vitro were not disrupted in buffers containing only nonionic detergents (low-stringency conditions).

The effects of detergent conditions on the association of Myc with Max in vitro prompted us to examine the manner in which detergents influenced the composition of anti-Myc and anti-Max immunoprecipitations from cells. Figure 4A shows a comparison of anti-c-Myc and anti-Max immunoprecipitates from Manca cells carried out under high- and low-stringency conditions. The immunocomplexes formed using high-stringency buffer contain either p64 c-Myc or p21/22 Max (Fig. 4A, HS). Reduction of the stringency of the buffer results in an increase in the background precipitation, as well as the appearance $\mathrm{p} 21 / 22$ in the anti-Myc precipitate and $\mathrm{p} 64$ in the anti-Max precipitate (Fig. 4A, LS). That these proteins are specifically precipitated is demonstrated by the ability of Max and Myc immunogens to competitively block their precipitation (Fig. 4A, b and LS), whereas the elevated background is unaffected. Furthermore, Figure $4 \mathrm{~A}(\alpha-\mathrm{Myc})$ shows that anti-Myc can cleanly precipitate Myc protein that has been released from a low-stringency anti-Max immunocomplex by the addition of SDS and deoxycholate. Similarly, anti-Max can precipitate Max protein released from the anti-Myc complex in the same manner (Fig. 4A, $\alpha$-Max). The ability of the antiMyc and anti-Max sera to precipitate the complex without disrupting it is consistent with our results on Myc:Max oligomers formed in vitro (Blackwood and Eisenman 1991). Two other points suggest that the association of Myc and Max does not occur during or after cell lysis. First, the lysis and coimmunoprecipitations are carried out at $4^{\circ} \mathrm{C}$, a temperature at which Myc and Max do not dissociate in vitro (E.M. Blackwood, unpubl.). Second, addition to the lysate of excess unlabeled Max protein, fully competent to dimerize, blocks precipitation of both Max and Myc (Fig. 4A,b), suggesting that subunit exchange is not appreciable under these conditions. We conclude from these experiments that Max and $\mathrm{Myc}$ are highly likely to be associated in vivo. Similarly, we have been able to demonstrate in vivo association between Max and N-Myc, as well as between different retrovirally encoded v-Myc proteins and Max (data not shown).

Considering the highly stable nature of Max, it was of interest to determine whether the short half-life of c-Myc might be affected by its association with Max. Myc protein stability was evaluated by pulse-chase experiments using BK3A cells, a chicken bursal lymphoma cell line in which Myc protein metabolism has been studied extensively (Lüscher and Eisenman 1988). After the 30-min pulse label, and at different time points during the chase period, the cells were lysed under lowstringency conditions and Myc proteins immunoprecipitated under high-stringency conditions with anti-Myc to determine the total amount of radiolabeled Myc present (Fig. 4B, left). In parallel, the amount of labeled Myc protein associated with Max was determined by immunoprecipiation with anti-Max under low-stringency conditions (Fig. 4B, center). Although Myc protein can be resolved under these conditions, we verified the amount of Myc present in the Max complex by treating the antiMax immunocomplex with high-stringency buffer followed by reimmunoprecipitation with anti-Myc (Fig. 4B, right). The results show clearly that the majority of the newly synthesized Myc protein is present in the complex with Max and, furthermore, that the half-life of Myc is unchanged by its association with Max. It is important to bear in mind, however, that detergent lysis conditions might not extract all of the Myc protein.

Immunoprecipitated Myc:Max complexes specifically bind the CACGTG motif

Previous work had demonstrated that the Myc:Max 


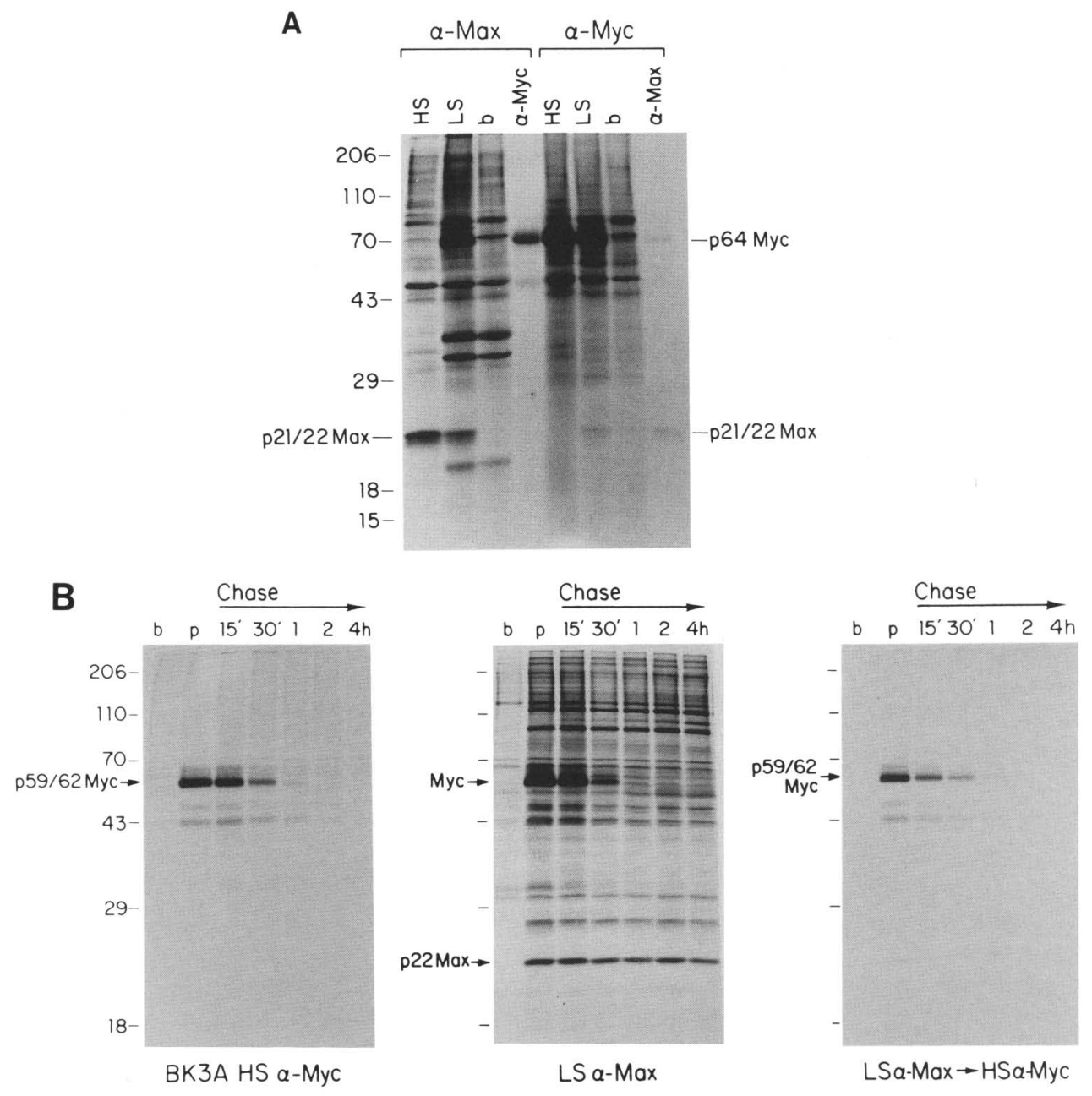

Figure 4. Identification and stability of Myc:Max complexes in vivo. $(A)\left[{ }^{35} S\right]$ Methionine-labeled Manca cell lysates were immunoprecipitated under high-stringency (HS) or low-stringency (LS) detergent conditions (see Materials and methods). An excess of the cognate immunogen was used to block specific immunoprecipitation (b). To verify the identity of the coprecipitated component, low-stringency Myc:Max complexes were dissociated with SDS and reimmunoprecipitated under high-stringency conditions with the converse antiserum $(\alpha-$ Myc or $\alpha$-Max). (B) The stability of Myc protein was analyzed by pulse-chase labeling (30-min pulse label) of BK3A, an avian bursal lymphoma cell line. Low-stringency extracts of Myc protein were directly immunoprecipitated under highstringency conditions (HS $\alpha-\mathrm{Myc}$ ) or coprecipitated in a complex with Max (LS $\alpha$-Max). To verify the levels of Myc protein found in anti-Max immunoprecipitates, low-stringency complexes were dissociated with ionic detergent and reprecipitated with anti-Myc (LS $\alpha-\operatorname{Max} \rightarrow \mathrm{HS} \alpha-\mathrm{Myc})$. Identical exposures are shown.

complex formed from in vitro-translated proteins was capable of binding a synthetic oligonucleotide (CM-1) containing the CACGTG site under conditions where neither Myc nor Max alone showed substantial binding (Blackwood and Eisenman 1991; Prendergast et al. 1991). We were interested in determining whether similar binding activity could be identified in cells. Gel-retardation analyses using nuclear extracts demonstrated rather strong binding to oligonucleotides containing this site; but as neither anti-Myc nor anti-Max antibodies influenced mobility it seems likely that such binding is the result of USF or other proteins known to bind this sequence (Carthew et al. 1985; Sawadogo and Roeder 1987). To avoid this background binding we prepared
anti-Max immunoprecipitates under low-stringency conditions, dissociated the immunocomplexes with guanidine $\mathrm{HCl}$, and renatured the proteins by dialysis into DNA-binding buffer as described previously (Lüscher et al. 1990; see Materials and methods). Both Myc and Max proteins are present in this immunoprecipitate, as verified by immunoblot analysis with anti-Myc and antiMax antibodies (Fig. 5, left).

When the anti-Max-immunoprecipitated material is used in gel-retardation assays the CM-1 oligonucleotide is bound in a major complex and a more slowly migrating minor complex. A similar degree of binding was detected for the EMS (E box, Myc site; Prendergast et al. 1991) oligonucleotide that contains the CACGTG 
Blackwood et al.

Figure 5. Specific DNA-binding activity of immunoprecipitated Myc:Max proteins. Anti-Max immunoprecipitates were prepared under low-stringency conditions from unlabeled $\mathrm{K} 562$ cells and, after denaturation and renaturation, were used in gel-retardation assays with two ${ }^{32}$ P-labeled synthetic oligonucleotides (CM-1 and EMS) containing the CACGTG-binding site but with different flanking sequences (see Materials and methods). (Left) Immunoblot of the initial anti-Max immunoprecipitate probed with a mixture of anti-Myc and antiMax antibodies and ${ }^{125} \mathrm{I}$-labeled protein $\mathrm{A}$. The left and right lanes are different exposures of the same blot, showing the presence of both $\mathrm{Myc}$ and $\mathrm{Max}$ proteins. The immunoglobulin band $(\mathrm{Ig})$ is detected through its reaction with the iodinated protein $\mathrm{A}$. Gel-retardation assays are shown with CM-1 (middle) and EMS (right).

flanked by a short sequence reputed to improve binding by Myc protein produced in vitro (Halazonetis and Kandil 1991). Binding to these CACGTG-containing oligonucleotides by the anti-Max-immunoprecipitated proteins is specific, as it is completely competed by excess unlabeled CM-1 and EMS but not by the muscle creatine kinase enhancer MyoD-binding site (MCK, differing by only 3 nucleotides from CM-11, salmon sperm DNA, or tRNA (Fig. 5, right). Poly[d(I-C)] also reproducibly competes for binding to CM-1 and EMS, but not as strongly as the CACGTG-containing oligonucleotides.

The retarded CM-1 oligonucleotide is complexed with both Myc and Max proteins. This was demonstrated by the ability of both affinity-purified anti-Max and antiMyc antibodies to block formation of the original faster migrating complexes and to produce a secondary shift to higher mobility (Fig. 5, middle). That the effects of the antibodies are specific is shown by the fact that they could be reversed by addition of competing amounts of the cognate Myc and Max immunogens (Fig. 5, middle; lanes labeled block). We note that the more slowly migrating complex is supershifted with anti-Max but not with anti-Myc. This band may represent residual Max protein complexed with the initial anti-Max antibodies used in the immunoprecipitate. It is also possible that other proteins may be present in these complexes in addition to Myc and Max. Regardless of the possible presence of other proteins, our data demonstrate that Myc:Max complexes with specific CACGTG-binding activity can be immunoprecipitated from cell lysates.

\section{Max expression during mitogenic stimulation} and the cell cycle

c-myc belongs to the class of immediate early genes in that although myc RNA and protein are virtually unde-
K562

IP Max
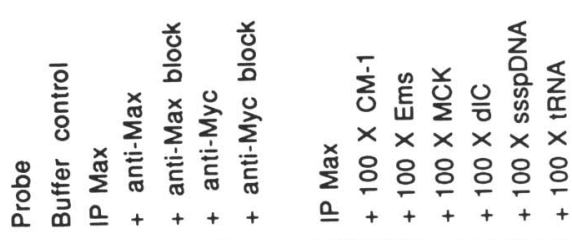

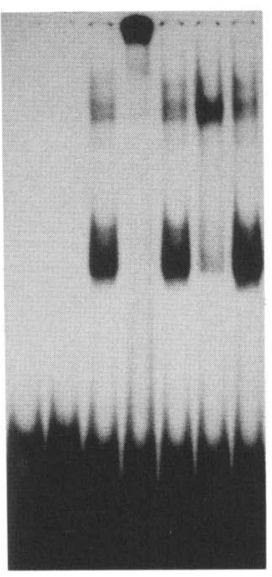

$\mathrm{CM}-1$

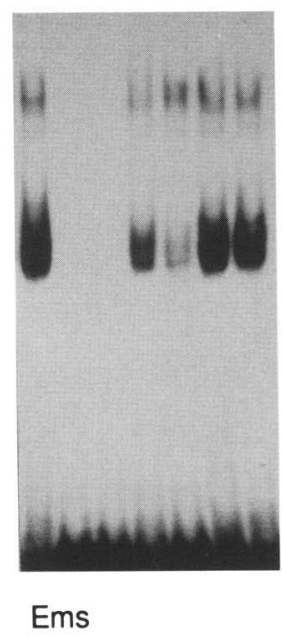

tectable in quiescent cells, they are induced transiently to high levels within several hours after mitogenic stimulation (Kelly et al. 1983; Dean et al. 1986; Clark et al. 1989). The peak of c-myc expression is followed by a decrease to a basal level that remains invariant throughout the cell cycle (Hann et al. 1985; Rabbitts et al. 1985; Thompson et al. 1985; Waters et al. 1991). Because c-myc and max are expressed in many of the same cell types we asked whether $\max$ was also an immediate early gene by examining its expression levels after mitogen stimulation of serum-starved A31 BALB/c-3T3 cells (see Materials and methods). Steady-state expression levels were determined by immunoblotting with anti-Max and by Northern blotting. Surprisingly, both Max protein and $\max$ RNA were readily detected in quiescent cultures (Fig. 6). Addition of serum clearly resulted in entry of cells into $G_{1}$ and $S$ phases, as judged by the 20 -fold increase in $\left[{ }^{3} \mathrm{H}\right] \mathrm{TdR}$ incorporation (Fig. 6) and an early increase in c-myc RNA (data not shown). No significant change in steady-state max RNA or protein levels, however, was observed.

To determine whether Max levels were modulated during the cell cycle itself we used centrifugal elutriation to obtain subpopulations of exponentially growing K562 cells enriched for different cell cycle fractions. Figure 7 (top) shows the DNA contents of the elutriated fractions, clearly demonstrating that we have obtained subpopulations of cells in $G_{1}, S$, and $G_{2} / M$ phases. When these cells were lysed and Myc:Max complexes were coprecipitated with anti-Myc or anti-Max under low-stringency conditions, we found that the steady-state levels of Max protein were unaltered during the cell cycle (Fig. 7, bottom). These data also indicate that the amount of Myc:Max complex does not change during the cell cycle. It is noteworthy that in contrast to the results with 


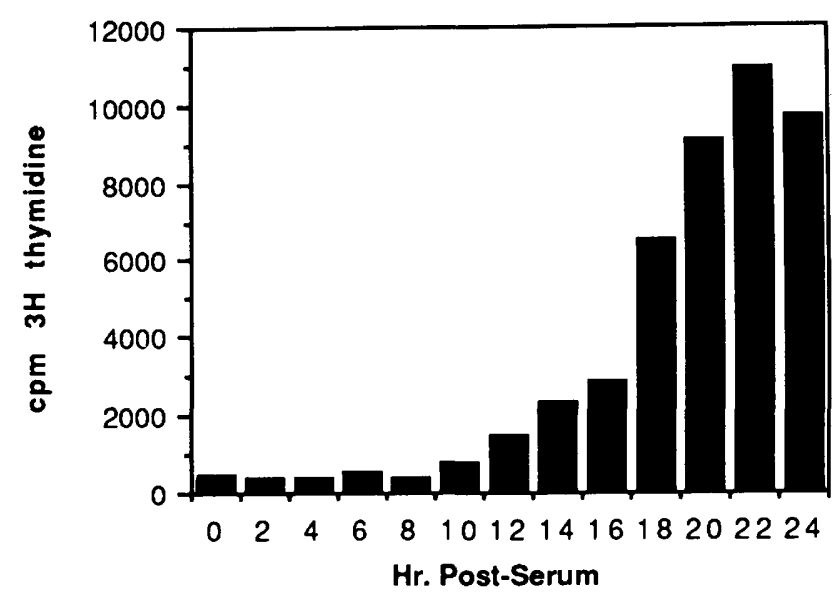

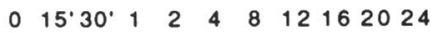

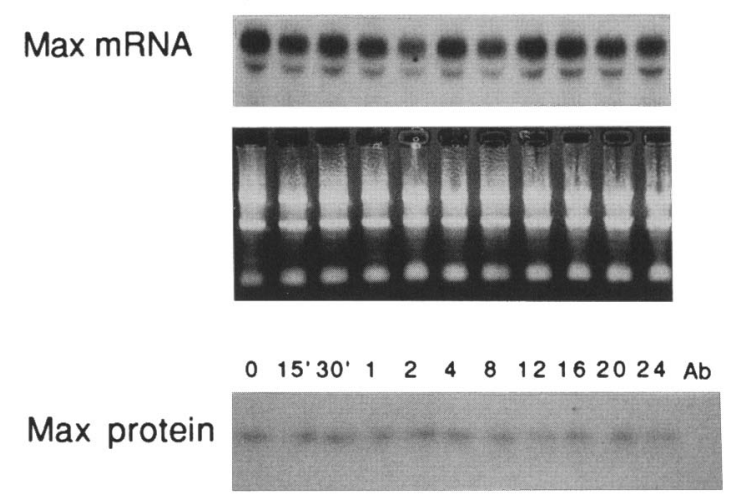

Figure 6. Analysis of Max protein and RNA levels during mitogen stimulation. A31 BALB/c-3T3 cultures were serum depleted for 5 days before stimulation with $15 \%$ fetal serum. $\left[{ }^{3} \mathrm{H}\right] \mathrm{TdR}$ incorporation was measured in 2-hr pulse labelings after addition of serum (top). Max mRNA levels were analyzed by Northern blotting, using the max cDNA as probe (Blackwood and Eisenman 1991). An ethidium bromide-stained agarose gel was used to normalize the amount of RNA $(10 \mu \mathrm{g}$, middle $)$. To monitor steady-state levels of Max protein, anti-Max immunoprecipitates (from unlabeled cells) were resolved by SDS-PAGE, transferred to nitrocellulose, and reprobed with anti-Max and ${ }^{125}$ I-labeled protein A (bottom). Anti-Max antibody serves as a control for ${ }^{125}$ I-labeled protein A-reactive immunoglobulin (Ab). The time course is in minutes (') or hours after serum addition.

pulse-labeled cells (Fig. 4A,B), our immunoblotting experiments do not detect quantitative association between Myc and Max (Fig. 7). This may be explained by a preferential association of newly synthesized Myc with Max, whereas Myc protein detected by immunoblotting could represent both newly synthesized protein as well as older molecules released from the complex. Taken together, our data demonstrate that Max is not a member of the class of mitogen-inducible genes, and its levels of expression are independent of cell growth.

\section{Discussion}

We have identified the Myc-binding protein Max in vivo and have shown that Myc and Max are associated in the cell. The complex between Myc and Max is a dynamic one in that Myc protein turns over rapidly, whereas Max appears to remain highly stable. In addition, Max expression appears to be independent of the growth state of the cell. Max protein and RNA are readily detected in quiescent cells at levels that are unchanged by serum stimulation or cell cycle phase. In contrast, mitogenic stimulation has long been known to result in an increase in Myc levels from near background in quiescent cells to a peak of expression that declines to a basal level before $S$ phase (Kelly et al. 1983; Dean et al. 1986). During the cell cycle, Myc synthesis and rapid turnover have been shown to be maintained at a constant basal level (Hann et al. 1985; Rabbitts et al. 1985; Thompson et al. 1985; Waters et al. 1991), and we show here that Max levels also do not vary during the phases of the cell cycle. In addition, it would appear that the ability of Myc and Max to form a hetero-complex is not modulated as a function of the cell cycle. We have also carried out coimmunoprecipitation experiments with results indicating that the virally encoded $\mathrm{v}-\mathrm{Myc}$ transforming proteins, as well as N-Myc, are associated with Max in cells (data not shown). Together with data indicating that N-Myc, c-Myc, and L-Myc associate with Max in vitro (Blackwood and Eisenman 1991), this raises the possibility that all Myc family proteins might function in a complex with Max.

Previous work has demonstrated that mutations in the carboxy-terminal HLH domain of c-Myc, which inhibit its binding to Max (Blackwood and Eisenman 1991; Prendergast et al. 1991), also abolish the biological activity of Myc as measured by cotransformation, inhibition of differentiation, and autoregulation (for review, see Penn et al. 1990; Lüscher and Eisenman 1990). As most, if not all, of the newly synthesized Myc protein passes through a complex with Max we believe that Myc exerts its biological functions through its association with Max. Genetic evidence, such as the effects of in vivo inactivation of Max through gene deletion or introduction of dominant-negative Max proteins, however, will be required to formally demonstrate that Max is indispensible to the function of Myc.

The contrasting properties of Myc and Max suggest that it is the abundance of Myc that limits or drives formation of heterocomplexes. In vitro studies indicate that Max homodimerizes but will preferentially associate with Myc, which homodimerizes poorly, if at all (Blackwell et al. 1990; Smith et al. 1990; Blackwood and Eisenman 1991; E.M. Blackwood, unpubl.). In vivo shortlived Myc monomers may be continually competing with Max homodimers for interaction with Max. One possibility is that Max homodimers function in a manner distinct from Myc:Max heterodimers and that Myc serves to transiently "switch" Max between its different activities. Thus, the extraordinary degree to which Myc expression is regulated and the loss of this regulation during oncogenic activation (for review, see Spencer and Groudine 1990) may critically influence the balance between heterodimer and homodimer function. 
Blackwood et al.

Figure 7. Analysis of Myc:Max complex formation during the cell cycle. An exponentially growing culture of the human erythroleukemia cell line, K562, was subjected to centrifugal elutriation, and sizefractionated subpopulations were monitored for DNA content after propidium iodide staining. (Top) The DNA contents of the different subpopulations; (bottom) lowstringency immunoprecipitates with antiMyc and anti-Max sera from each fraction were immunoblotted with a mixture of anti-Myc and anti-Max and iodinated protein A. Asynchronous cells (Asyn) are from a nonelutriated exponentially growing population; antibody alone $(\mathrm{Ab})$ in the absence of cell lysate served as a control for the position of iodinated protein A-reactive immunoglobulin.
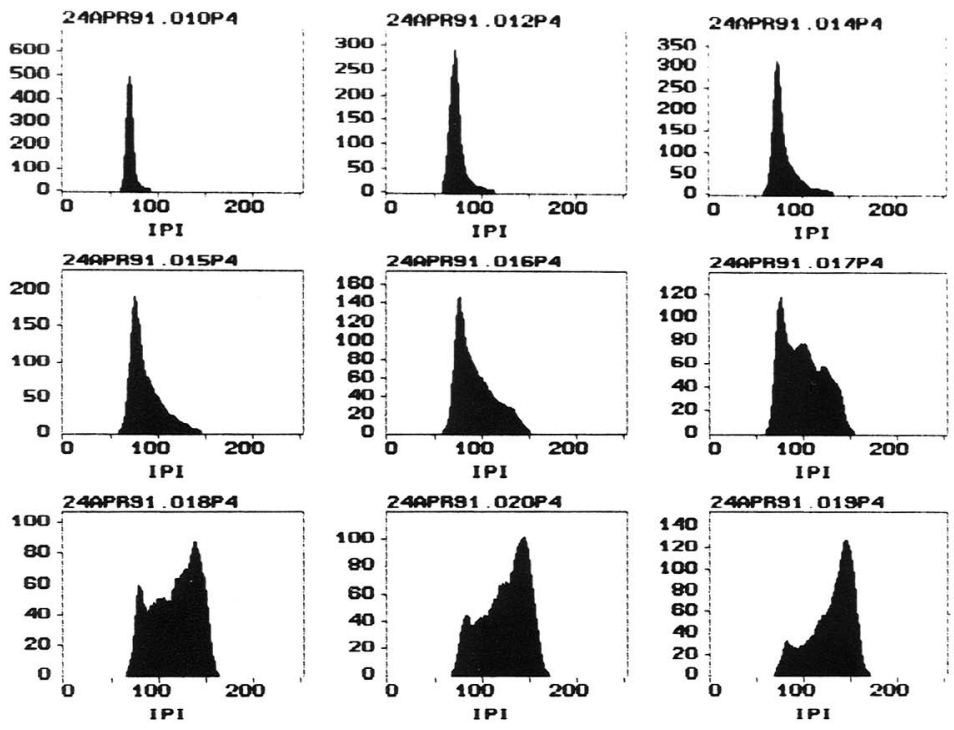

Anti-Myc

Anti-Max

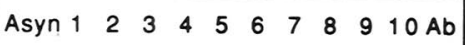

$\begin{array}{llllllllllll}\text { Asyn } 1 & 2 & 3 & 4 & 5 & 6 & 7 & 8 & 9 & 10 & \mathrm{Ab}\end{array}$
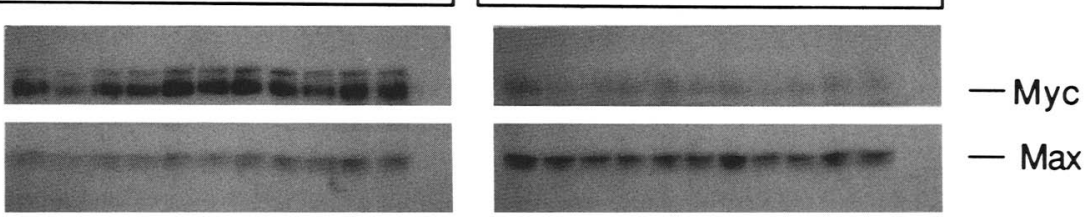

It will be of interest to determine whether complex formation or function is regulated by other factors, such as CKII phosphorylation, the expression pattern of two alternative Max proteins, or potential interactions with other cellular components. Recently, it has been shown that the amino-terminal region of $\mathrm{Myc}$, which is thought to function as a transcriptional activator region (Kato et al. 1990), can associate with p105Rb in an in vitro-binding assay (Rustgi et al 1991). We note anti-Max and antiMyc immunoprecipitates, performed under conditions that permit Myc:Max association, also contain a number of other proteins, some of which might be specifically associated with the complex. To date, we have been unable to detect p105Rb among these proteins (E.M. Blackwood, unpubl.l, suggesting that its association with Myc is either of lower affinity than that of Max or that only a small fraction of $\mathrm{Rb}$ is complexed. Nonetheless, the ability to isolate Myc:Max oligomers having specific DNAbinding activity from cells, may provide a means of copurifying other factors that operate in conjunction with a Myc:Max nucleoprotein complex.

\section{Materials and methods}

\section{Antibodies and immunogens}

GST-MaxC124 was constructed, purified, and used to generate a polyclonal rabbit antisera as described previously (Blackwood and Eisenman 1991). Affinity-purified antibodies to the 12 car- boxy-terminal amino acids of human c-Myc (anti-Myc) have been characterized elsewhere (Hann and Eisenman 1984).

\section{Immunoprecipitations}

Cell lines were metabollically labeled for $30-60 \mathrm{~min}$ with ${ }^{35} \mathrm{~S}$ containing amino acids. Standard high-stringency immunoprecipitations were carried out as described previously (Lüscher et al. 1989]. Briefly, cells were lysed in Ab buffer [20 mM Tris- $\mathrm{HCl}$ $(\mathrm{pH} 7.4), 50 \mathrm{~mm} \mathrm{NaCl}, 1 \mathrm{~mm}$ EDTA, $0.5 \%$ NP-40, $0.5 \%$ deoxycholate, $0.5 \%$ SDS, $0.5 \%$ aprotinin], sonicated, clarified by centrifugation, and subjected to immunoprecipitation with saturating amounts of antibody. Immunocomplexes were collected using protein A-Sepharose CL4B (Sigma). The resin was washed twice with RIPA buffer [10 mM Tris (pH 7.4), $150 \mathrm{~mm} \mathrm{NaCl}, 1 \%$ NP-40, $1 \%$ deoxycholate, $0.1 \%$ SDS, $0.5 \%$ aprotinin], once with high salt buffer [ $2 \mathrm{M} \mathrm{NaCl}, 10 \mathrm{~mm}$ Tris (pH 7.4), $1 \% \mathrm{NP}-40,0.5 \%$ deoxycholatel and, finally, with RIPA buffer.

To increase the specific activity of the Max polypeptides for low-stringency immunoprecipitations, cells were metabolically labeled for a minimum of $1 \mathrm{hr}$. All subsequent steps were performed at $4^{\circ} \mathrm{C}$ to stabilize Myc:Max complexes. Washed cells were lysed in PBS containing 1\% NP-40 and a cocktail of protease and phosphatase inhibitors $(0.2 \mathrm{~mm}$ phenylmethylsulfonyl fluoride, $0.7 \mu \mathrm{g} / \mathrm{ml}$ of pepstatin, $0.5 \%$ aprotinin, $10 \mathrm{mM} \mathrm{NaF}, 50$ $\mathrm{mM} \beta$-glycerophosphate). The lysate $\left(1 \times 10^{7}\right.$ cells $\left./ \mathrm{ml}\right)$ was sonicated on ice and microcentrifuged to clarify. Cell equivalents $\left(5 \times 10^{6}\right)$ were immunoprecipitated with anti-Myc or anti-Max and collected on protein A-Sepharose beads. Low-stringency buffer was used to wash the precipitate four times. The nonim. munoreactive component of the complex was dissociated with 
$0.5 \mathrm{ml}$ of $\mathrm{Ab}$ buffer and reprecipitated under high-stringency conditions.

All SDS-PAGE samples were resolved on $15 \%$ polyacrylamide gels under reducing conditions.

\section{Peptide mapping}

For two-dimensional tryptic peptide analysis, Max proteins were immunoprecipitated either from radiolabeled cells or from in vitro-translated Max cDNA (Blackwood and Eisenman 1991). The precipitates were treated with alkaline phosphatase before gel purification and peptide mapping using published protocols (Lüscher et al. 1989).

\section{Nuclear localization}

Indirect immunofluorescence staining was performed on fixed HeLa cells using methods described previously (Palmer and Margolis 1985). Briefly, cells were fixed with paraformaldehyde, permeabilized with Triton X-100, blocked with bovine serum albumin, and incubated with affinity-purified anti-Max or polyclonal anti-Myc sera. Fluorescein-conjugated goat anti-rabbit immunoglobulin was used as the secondary reagent.

\section{Protein stability assays}

For analysis of protein and complex stability, cells were pulselabeled with $\left[{ }^{35} \mathrm{~S}\right]$ methionine for $30 \mathrm{~min}$, washed free of unmetabolized radiolabel, and chased in the presence of excess cold methionine $(0.5 \mathrm{mM})$. At specified time points, lysates were prepared in low-stringency buffer, immunoprecipitated under either high- or low-stringency conditions, and analyzed by SDSPAGE.

\section{Gel-retardation analysis of immunoprecipitated proteins}

Myc:Max complexes were isolated from K526 cells by lowstringency immunoprecipitation using anti-Max serum. The immunoprecipitates were eluted from protein A-Sepharose by denaturation with $6 \mathrm{M} \mathrm{Gu}-\mathrm{HCl}$ and renatured by exhaustive dialysis against $20 \mathrm{~mm}$ HEPES (pH 7.2), $25 \mathrm{~mm} \mathrm{KCl}, 1 \mathrm{~mm}$ $\beta$-mercaptoethanol, $10 \%$ glycerol, and $0.01 \% \mathrm{NaN}_{3}$. These preparations $\left(2 \times 10^{5}\right.$ cell equivalents $\left./ \mu 1\right)$ were stored at $-80^{\circ} \mathrm{C}$. To analyze the DNA-binding properties of the renatured material, $10 \mu \mathrm{l}$ of the preparation was used in an electrophoretic gel mobility-shift assay with $0.2 \mathrm{ng}$ of phosphorylated CM-1 or EMS oligonucleotide. Final conditions in the gel shift were 20 mM HEPES (pH 7.2), $50 \mathrm{~mm} \mathrm{KCl}, 1 \mathrm{mM}$ EDTA, $3 \mathrm{mM} \mathrm{MgCl}_{2}$, and $10 \%$ glycerol. As nonspecific competitor, $150 \mathrm{ng}$ of an unrelated single-stranded oligonucleotide was used in each reaction. $\mathrm{Nu}$ cleoprotein complexes were resolved by electrophoresis in a $4 \%$ acrylamide gel $(1 \times$ TBE). Affinity-purified antibodies were used to supershift the complexes as described previously (Blackwood and Eisenman 1991).

\section{Serum stimulation}

Quiescent A31 BALB/c-3T3 cells were serum stimulated as described previously (Greenburg and Ziff 1984). $\left[{ }^{3} \mathrm{H}\right] \mathrm{TdR}$ incorporation was measured in triplicate from 24-well plates as described (Bowen-Pope and Ross 1982). Total RNA was extracted by the acid/guanidinium isothiocyanate/phenol/chloroform procedure (Chomcznski and Sacchi 1987). For Northern analysis, $10 \mu \mathrm{g}$ of RNA was resolved by formaldehyde gel electrophoresis, transferred to a nylon membrane, and hybridized with a 560-bp Max probe. For analysis of steady-state protein levels,
Max polypeptides were immunoprecipitated from unlabeled cultures $\left\{3 \times 10^{6}\right.$ cells $\}$, resolved by SDS-PAGE, blotted to nitrocellulose, and reprobed with anti-Max and ${ }^{125} \mathrm{I}$-labeled protein A.

\section{Cell cycle analysis}

An exponentially growing culture of K562 erythroleukemia cells was elutriated by counterflow centrifugation into 10 fractions. Low-stringency lysates were prepared from $10^{7}$ cells, and anti-Myc or anti-Max was used to immunoprecipitate complexes. Steady-state protein levels were determined by Western blotting and reprobing with anti-Myc, anti-Max, and ${ }^{125} \mathrm{I}-\mathrm{la}$ beled protein A. The DNA content of each enriched fraction was determined by FACS analysis of propidium iodide-stained cells

\section{Acknowledgments}

We thank P. Andreasson, E. Firpo, A. Koff, D. Litchfield, R. Marraccino, and M. Schwab for kind gifts of reagents and $P$. Goodwin for image analysis. We are also grateful to D. Ayer, K. Blackwell, J. Cooper, C. Grandori, and R. Sternglanz for critical readings of the manuscript. This work was supported by the Molecular Training Program in Cancer Research at the University of Washington [National Institutes of Health (NIH) grant T32 CA09437] (E.M.B.) and NIH grant RO1 CA20525 (R.N.E.).

The publication costs of this article were defrayed in part by payment of page charges. This article must therefore be hereby marked "advertisement" in accordance with 18 USC section 1734 solely to indicate this fact.

\section{References}

Abrams, H., L. Rohrschneider, and R.N. Eisenman. 1982. Nuclear location of the putative transforming protein of avian myelocytomatosis virus. Cell 29: 427-439.

Benezra, R., R.L. Davis, D. Lockshon, D.L. Turner, and H. Weintraub. 1990. The protein Id: A negative regulator of helixloop-helix DNA binding proteins. Cell 61: 49-59.

Blackwell, T.K., L. Kretzner, E.M. Blackwood, R.N. Eisenman, and H. Weintraub. 1990. Sequence-specific DNA-binding by the c-Myc protein. Science 250: 1149-1151.

Blackwood, E.M. and R.N. Eisenman. 1991. Max: A helix-loophelix zipper protein that forms a sequence-specific DNA binding complex with Myc. Science 251: 1211-1217.

Bowen-Pope, D.F., and R. Ross. 1982. Platelet-derived growth factor. II. Specific binding to cultured cells. I. Biol. Chem. 257: 5161-5171.

Carthew, R.W., L.A. Chodosh, and P.A. Sharp. 1985. An RNA polymerase II transcription factor binds to an upstream element in the adenovirus major late promoter. Cell 43: 439448.

Chomcznski, P. and N. Sacchi. 1987. Single-step method of RNA isolation by acid guanidinium thiocyanate-phenolchloroform extraction. Anal. Biochem. 162: 156-159.

Clark, E.A., G. Shu, B. Lüscher, K.E. Draves, K.E. Banchereau, J. Ledbetter, and M.A. Valentine. 1989. Activation of human B cells: Comparison of the signal transduced by IL- 4 to four different competence signals. J. Immunol. 143: 3373-3380.

Dang, C.V., M. McGuire, M. Buckmire, and W.M.F. Lee. 1989. Involvement of the "leucine zipper" region in the oligomerization and transforming activity of human c-myc protein. Nature 337: 664-666.

Davis, R.L., P.-F. Cheng, A.B. Lassar, and H. Weintraub. 1990. 
The MyoD DNA binding domain contains a recognition code for muscle-specific gene activation. Cell 60: 733-746.

Dean, M., R.A. Levine, W. Ran, M.S. Kindy, G.E. Sonenshein, and J. Campsisi. 1986. Regulation of c-myc transcription and mRNA abundance by serum growth factors and cell contact. I. Biol. Chem. 261: 9161-9166.

Eisenman, R.N. 1989. Nuclear oncogenes. In Oncogenes and the molecular origins of cancer (ed. R.A. Weinberg), pp. 175221. Cold Spring Harbor Laboratory Press, Cold Spring Harbor, New York.

Eisenman, R.N., C.Y. Tachibana, H.D. Abrams, and S.R. Hann. 1985. v-myc and c-myc-encoded proteins are associated with the nuclear matrix. Mol. Cell. Biol. 5: 114-126.

Greenberg, M.E. and E.B. Ziff. 1984. Stimulation of 3T3 cells induces transcription of the c-fos proto-oncogene. Nature 311: $433-438$.

Halazonetis, T.D. and A.N. Kandil. 1991. Determination of the c-MYC DNA-binding site. Proc. Natl. Acad. Sci. 88: 61626166.

Hann, S.R. and R.N. Eisenman. 1984. Proteins encoded by the human c-myc oncogene: Differential expression in neoplastic cells. Mol. Cell. Biol. 4: 2486-2497.

Hann, S.R., H.D. Abrams, L.R. Rohrschneider, and R.N. Eisenman. 1983. Proteins encoded by v-myc and c-myc oncogenes: Identification and localization in acute leukemia virus transformants and bursal lymphoma cell lines. Cell 34: 789-798.

Hann, S.R., C.B. Thompson, and R.N. Eisenman. 1985. c-myc oncogene protein synthesis is independent of the cell cycle in human and avian cells. Nature 314: 366-369.

Jones, N. 1990. Transcriptional regulation by dimerization: Two sides to an incestuous relationship. Cell 61: 9-11.

Kato, G.J., J. Barrett, M. Villa-Garcia, and C.V. Dang. 1990. An amino-terminal c-Myc domain required for neoplastic transformation activates transcription. Mol. Cell. Biol. 10: 5914 5920.

Kelly, K., B.H. Cochran, C.D. Stiles, and P. Leder. 1983. Cellspecific regulation of the c-myc gene by lymphocyte mitogens and platelet-derived growth factor. Cell 35: 603-610.

Kerkhoff, E., K. Bister, and K.-H. Klempnauer. 1991. Sequencespecific DNA binding by Myc proteins. Proc. Natl. Acad. Sci. 88: 4323-4327.

Kuenzel, E.A., J.A. Mulligan, J. Sommercom, and E.G. Krebs. 1987. Substrate specificity determinants for casein kinase II as deduced from studies with synthetic peptides. J. Biol. Chem. 262: 9136-9140.

Lüscher, B. and R.N. Eisenman. 1988. c-myc and c-myb protein degradation: Effect of metabolic inhibitors and heat shock. Mol. Cell. Biol. 8: 2504-2512.

1990. New light on Myc and Myb. Part I. Myc. Genes \& Dev. 4: 2025-2035.

Lüscher, B., E.A. Kuenzel, E.G. Krebs, and R.N. Eisenman. 1989. Myc oncoproteins are phosphorylated by casein kinase II. EMBO I. 8: 1111-1119.

Lüscher, B., E. Christenson, D.W. Litchfield, E.G. Krebs, and R.N. Eisenman. 1990. Myb DNA binding inhibited by phosphorylation at a site deleted during oncogenic activation. Nature 344: 517-522.

Moerschell, R.P., Y. Hosokawa, S. Tsunasawa, and F. Sherman. 1990. The specificities of yeast methionine aminopeptidase and acetylation of amino-terminal methionine in vivo. $J$. Biol. Chem. 265: 19638-19643.

Palmer, D.K., and R.L. Margolis. 1985. Kinetochore components recognized by human autoantibodies are present on a mononucleosome. Mol. Cell. Biol. 5: 173-186.

Penn, L.J.Z., E.M. Laufer, and H. Land. 1990. C-MYC: Evidence for multiple regulatory functions. Semin. Cancer Biol. 1: 69-87.

Prendergast, G.C., and E.B. Ziff. 1991. Methylation-sensitive sequence-specific DNA binding by the c-Myc basic region. Science 251: 186-189.

Prendergast, G.C., D. Lawe, and E.B. Ziff. 1991. Association of Myn, the murine homolog of Max, with c-Myc stimulates methylation-sensitive DNA binding and Ras cotransformation. Cell 65: 395-407.

Rabbitts, P.H., J.W. Watson, A. Lamond, A. Forster, M.A. Stinson, G. Evan, W. Fischer, E. Athertton, M.A. Sheppard, and T.H. Rabbitts. 1985. Metabolism of c-myc gene products: c-myc mRNA and protein expression in the cell cycle. EMBO I. 4: 2009-2015.

Ramsay, G., L. Stanton, M. Schwab, and J.M. Bishop. 1986. Human proto-oncogene $\mathrm{N}$-myc encodes nuclear proteins that bind DNA. Mol. Cell. Biol. 6: 4450-4457.

Rustgi, A.K., N. Dyson, and R. Bernards. 1991. Amino-terminal domains of $\mathrm{c}-\mathrm{myc}$ and $\mathrm{N}$-myc proteins mediate binding to the retinoblastoma gene product. Nature 352: 541-544.

Sawadogo, M. and R. G. Roeder. 1985. Interaction of a genespecific transcription factor with the adenovirus major late promoter upstream of the TATA box region. Cell 43: 165175.

Smith, M.J., D.C. Charron-Prochownik, and E.V. Prowchownik. 1990. The leucine zipper of c-Myc is required for full inhibition of erythroleukemia differentiation. Mol. Cell. Biol. 10: $5333-5339$.

Spencer, C.A. and M. Groudine. 1990. Control of c-myc regulation in normal and neoplastic cells. Adv. Cancer Res. 56: 148.

Thompson, C.B., P.B. Challoner, P.E. Neiman, and M. Groudine. 1985. c-myc mRNA levels are independent of the cell cycle. Nature 314: 363-366.

Waters, C.M., T.D. Littlewood, D.C. Hancock, J.P. Moore, and G.I. Evan. 1991. c-myc protein expression in untransformed fibroblasts. Oncogene 6: 797-805. 


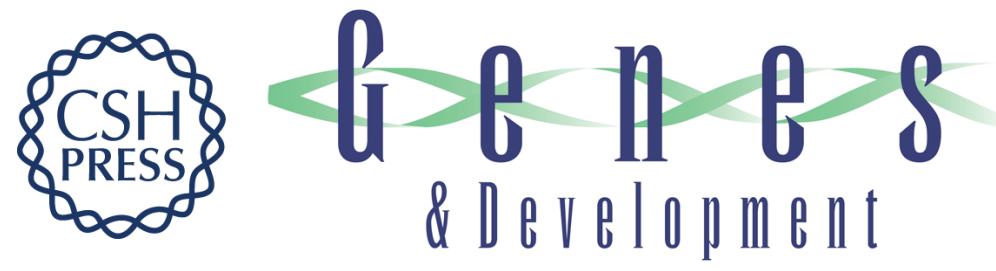

\section{Myc and Max associate in vivo.}

E M Blackwood, B Lüscher and R N Eisenman

Genes Dev. 1992, 6:

Access the most recent version at doi:10.1101/gad.6.1.71

References This article cites 39 articles, 17 of which can be accessed free at: http://genesdev.cshlp.org/content/6/1/71.full.html\#ref-list-1

\section{License}

Email Alerting

Receive free email alerts when new articles cite this article - sign up in the box at the top Service right corner of the article or click here.

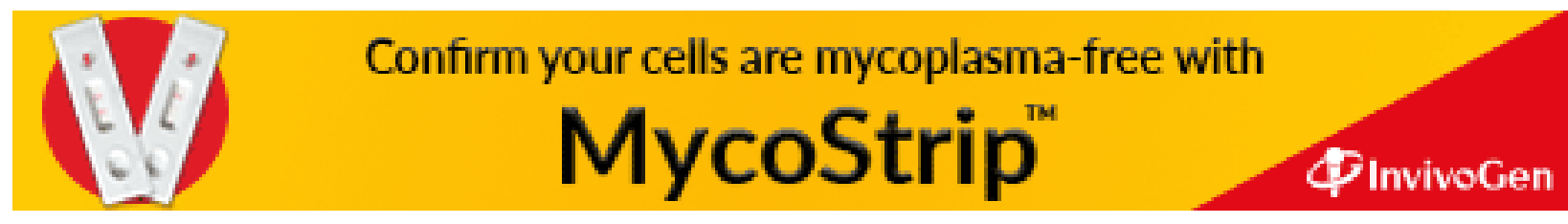

